\title{
Influence of intravenous Egyptian fennel honey infusion on the antioxidant activities and some haemo-indices in healthy goats
}

\begin{abstract}
As apitherapeutic use of honey has been reborn into modern medicine, the concept of its I/V administration must be fully studied. The objective of the work was to evaluate whether the intravenous (I/V) honey infusion in healthy goats affects the levels of antioxidants, free radicals scavenging and haemo-indices. Eight apparently healthy female goats were rapidly intravenously infused (70-80 drops/min.) with fennel honey solution $20 \%$ in sterile normal saline day by day for three successive times. By the second dose, the infusion was guarded by antihistaminic administration. The antioxidants [glutathion peroxidase (GPX), superoxide dismutase (SOD) and ascorbic acid), free radical metabolites through malonaldehyde (MDA) production and some haemo-indices [total leucocytic count (TWBCs), differential leucocytic count and serum globulins] were determined every week up to four weeks. I/V honey infusion increased significantly $(\mathrm{P}<0.05)$ GPX, SOD, serum globulins, TWBCs count, lymphocytes and monocytes percentages. However, it decreased significantly $(\mathrm{P}<0.05)$ the MDA levels and none significantly increased ascorbic acid levels. It was concluded that intravenous fennel honey infusion in goats would: a) Increase the activity of antioxidants GPX and SOD. b) Acts as scavenge free radicals by decreasing MDA levels. c) Improves haemo-indices by the increase of TWBCs count, lymphocytes and monocytes percentages and serum globulins level. All these desired obtained results were achieved by the fourth week post infusion.
\end{abstract}

Keywords: fennel honey, antioxidants, intravenous infusion, haemo-indices
Volume II Issue 5 - 2018

\author{
Mohamed Abd-El Mooty,' Neveen A. EL \\ Nisr, ${ }^{2}$ Nahed MWahba, ${ }^{2}$ Hamouda SM, ${ }^{2}$ \\ Ghada A Abou El-Ella, ${ }^{3}$ Wallaa M El-Sherif, ${ }^{2}$ \\ Abd El Rahman MF, ${ }^{4}$ Abd El Hafeez MM, ${ }^{2}$ \\ Ahmed Abd El Fattah Aamer ${ }^{3}$ \\ 'Department of Biochemistry, Soagh University, Egypt \\ ${ }^{2}$ Animal Health Research Institute (AHRI) Assiut, Egypt \\ ${ }^{3}$ Department of Medicine, Assiut University, Egypt \\ ${ }^{4}$ Plant Protection Research Institute, Egypt
}

Correspondence: Abd El Hafeez MM,Animal Health Research Institute (AHRI) Assiut, Egypt, Email mohhafeez5555@gmail.com

Received: October 08, 2018 | Published: October 15, 2018

\section{Introduction}

It was mentioned in the Holy Quran that bees produce drink of varying colours that cure illness (Surat Al-Nahl, Aya 69). Honey in ancient medicine proved its potency and its therapeutic use is widely documented since it is adopted as antimicrobial, anti-inflammatory, antioxidant and promotes wound healing ${ }^{1}$ by different application routes; topical application, ${ }^{2,3}$ oral administration, ${ }^{4,5}$ intravenous, ${ }^{6-8}$ intramammary, ${ }^{9,10}$ intrauterine infusion ${ }^{11,12}$ as well as intrapulmonary inhalation. $^{?}$

Among different unifloral honey types, manuka honey ${ }^{13,14}$ from New Zealand has the strongest antioxidant activity. Tualang, ${ }^{15}$ nenas ${ }^{16}$ and gelam ${ }^{17}$ honey from Malysian, sundarban ${ }^{18}$ honey from Bangladesh, acacia, ${ }^{19}$ seder ${ }^{19,20}$ honeys from Saudi Arabia, jelly bush, tea tree, super manuka and jarrah honeys ${ }^{21}$ from Australia, lychee flower $^{22}$ honey from China and multifloral ${ }^{23}$ honey from Ethiopia, Egyptian cotton, eucalyptus, black seed, ${ }^{24}$ and coriander ${ }^{25}$ and Spanish citrus $^{26}$ honeys proved to possess antioxidant activity with different potencies.

\section{Material and methods}

\section{Animals}

Eight apparently healthy female goats 4-5 months old weighing about $10-24 \mathrm{~kg}$ body weight were examined for clinically health investigations and be chosen for this study. Animals were left for two weeks before the study under strict clinical observations in an isolated pen, fed on concentrated ration, rice straw and water adlib/ Animal daily.

\section{Honey}

Fresh Egyptian fennel honey was used in the study. It was collected from an apiary in Assiut Governorate where a wide area of fennel was cultivated. Honey microscopically tested for floral pollen grains. Unprocessed honey ( $2 \mathrm{~g} / \mathrm{Kg}$ body weight for every infused animal) was diluted with sterile normal saline solution to achieve $20 \%$ honey solution then, it was filtered under complete aseptic conditions using sterilized filter papers to remove any debris, wax, or large particles for the I/V infusion.?

\section{I/V honey infusion}

Honey solution was infused through jugular vein 70-80 drops/ min as rapid infusion ${ }^{7}$, once daily and repeated day by day for three successive times. Animals were observed and inspected closely for any abnormal clinical manifestations.

Blood sampling: Two blood samples were collected from each goat before the study; one was with anticoagulant for hematological study and the other without to obtain their own sera. Blood sampling was repeated post the first honey infusion at four times weekly intervals. Hematological study included determination of total leucocytic count (TWBCs), percentages of band cells, segmented neutrophils, lymphocytes, eosinophils, basophils and monocytes. Serum samples were assayed for total proteins and total albumin contents to obtain their own total serum globulins.

\section{Antioxidant investigation}

Determination of lipid peroxidation through MDA production was adopted using a colorimetric assay with the thiobarbituric acid reactive 
substance (TBARS), ${ }^{29}$ and defined as ng/ml. GPX ${ }^{30}$ and SOD $^{31}$ were assayed by the spectrophotometric methods, and their activities were given in units (U/mg protein). Serum ascorbate concentration was measured $^{32}$ and defined as $\mathrm{mg} / \mathrm{dl}$.

\section{Statistical analysis}

All achieved data were expressed as means \pm SD. Statistical data analysis was done using ANOVA one way Mstat-C software. ${ }^{33}$ Posthoc analysis were done using Duncan's Multiple Range test at $\mathrm{p}<0.05$. The significant values of the treatments with the control group are expressed in $(*)$.

\section{Results and discussion}

During normal metabolic functions, highly reactive compounds called free radicals are created in the body differ from most biological molecules by having unpaired electrons. ${ }^{8}$ So, they tend to react with other body chemicals and called reactive species (ROS oxygen - which are highly reactive). ${ }^{34,35}$ The imbalance between oxidative stress and antioxidant scavengers leads to damage of important biomolecules in the cells, where lipids are biomolecules representing a significant target for ROS attack generating other reactive species such as MDA and can increase the risk of mutagenesis ${ }^{36}$ and the body has a defense mechanism against its harmful effects through neutralizing the free radicals by means of either endogenous [e.g., glutathione peroxidase (GPX), superoxide dismutase (SOD), glutathione reductase (GR), and catalase (CT)], ${ }^{37}$ or exogenous from the diet e.g. flavonoids, ${ }^{38}$ selenium, ${ }^{39}$ vit. C and vit. E. ${ }^{40}$ Additional endogenous sources of cellular ROS are neutrophils, esinophils and macrophages which on activation initiate an increase in oxygen uptake giving rise to a variety of ROS, nitric oxide and hydrogen peroxide. ${ }^{41}$

As mentioned in the premise, honey apitherapeutic use nowadays is widely spread and reborn into the modern medicine by its various different bioactive micro components ${ }^{42}$ such as flavonoids, ${ }^{43}$ phenolic compounds, ${ }^{44}$ chrysin ${ }^{45}$ and amino acids ${ }^{46}$ but the main antioxidants are considered to be the polyphenols. ${ }^{47}$ Honey chrysin ${ }^{45,48}$ as a polyphenolic compound enhanced protein stability, solid lipid nanoparticle (SLN) synthesis avoiding proteolytic degradation ${ }^{45}$ resulting antiploliferating ${ }^{49}$ and anti-inflammatory ${ }^{50}$ properties, where the honey antioxidant and antiradical activity correlates with the presence of these total phenol and flavonoids constituents. ${ }^{51}$

Although, the safeness of slow I/V (15 drops/min $)^{6}$ or rapid I/V. ${ }^{7}$ honey infusions in different concentrations was established in sheep, the present study faced a risky factor (25\%) where $10-15$ min post first the I/V honey infusion administration, allergic reactions were observed to two goats $(25 \%)$ including interrupted respiration, restlessness, nasal frothy secretions, chest edema and they died after thirty minutes, while the other 6 goats showed no reactions. But from the second infusion, the rest 6 animals (75\%) received honey solution $20 \%$ guarded with antihistaminic drug $(0.7 \mathrm{mg} / \mathrm{kg} \mathrm{B}$ wt. - Avil Retard, Aventis - Egypt). By the remaining two I/V honey infusions; animals were calm without any allergic manifestations or any adverse reactions up to the end of the study. Neutrophils and eosinophils which be increased by $\mathrm{I} / \mathrm{V}^{6}$ honey will participant in allergic diseases since these cells work as antigen presenting cells and can stimulate lymphocyte activity ${ }^{52}$. The rapid onset of systemic anaphylactic symptoms, suggests that basophiles, a circulating pool of cells containing histamine and other potent mediators such as leukotrienes, may be more involved in systemic anaphylaxis than originally thought. ${ }^{53}$
In the present study, by three successive intravenous fennel honey infusions in goats augmented its therapeutic effects by high antioxidant parameters - significantly increase of GPX (Figure 1) and SOD (Figure 2), while lowered MDA significantly (Figure 3) - by the 1 st, the 2 nd and the 3 rd week post intravenous infusion respectively. Manuka honey inhibited MDA in gastric ulcerated rats. ${ }^{54}$ Egyptian multifloral honey ${ }^{55}$ increased both GPX and SOD and decreased MDA levels in rats. Similar these positive results were obtained in healthy tested models as with Malaysian honeys (nenas H. in healthy university student, ${ }^{14}$ gelam $\mathrm{H}$. in young and aged rats ${ }^{57}$ or with tualang H. in normal male mice ${ }^{56}$ ). Moreover,the increased GPX and SOD with the decreased MDA was obtained with Malayian tualang honey in stressed oxidative smokers ${ }^{58}$ or female athletes ${ }^{61}$ and in animal induced stress oxidative ovariectomized ${ }^{59}$ or diabetic rats. ${ }^{60}$ Otherwise, Iranian multifloral honey ${ }^{62}$ ameliorated the increased MDA content and reduced the activity of SOD in stressed oxidative rats due to the inhibition of pro - inflammatory cytokines: TNF- $\square$, IL-1 $\square$, and IL-6 by the action of the polyphenols, flavonoids, and caffeic acid phenethyl ester. ${ }^{14}$ Flavonoids - polyphenolic compounds are a group of secondary metabolites naturally occurring in the plant kingdom, possess numerous pharmacological activities ${ }^{54}$ Most of the antioxidant benefits of honey are associated with the presence of polyphenols since there is high correlation between honey's biological activity and the polyphenolic content. ${ }^{36}$ Chrysin (5,7-dihydroxyflavone) is a dietary phytochemical abundantly present in many plant extracts, then in honey and propolis ${ }^{45}$ which evolved as promising pharmacological agents as it possesses potent anti-inflammatory ${ }^{63}$ and antioxidant properties $^{45,64}$ with direct positive effect on GPX, SOD and MDA. ${ }^{64}$

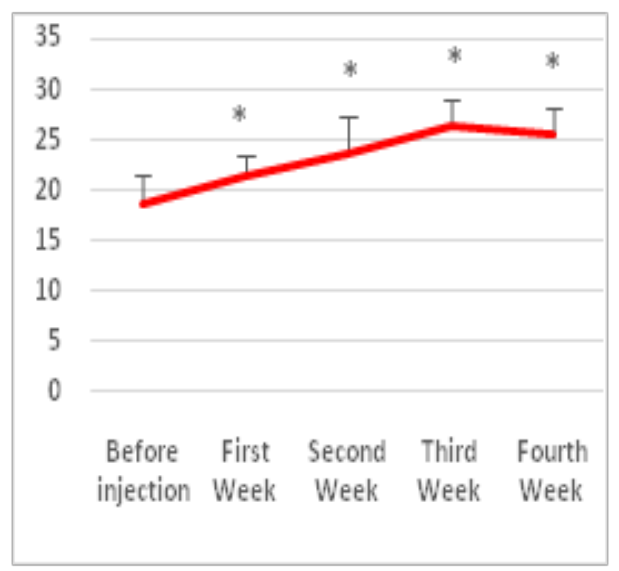

Figure I GPX.

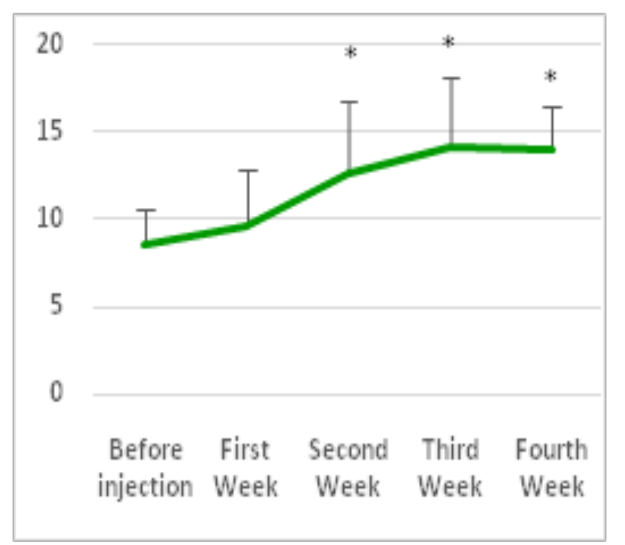

Figure 2 SOD. 


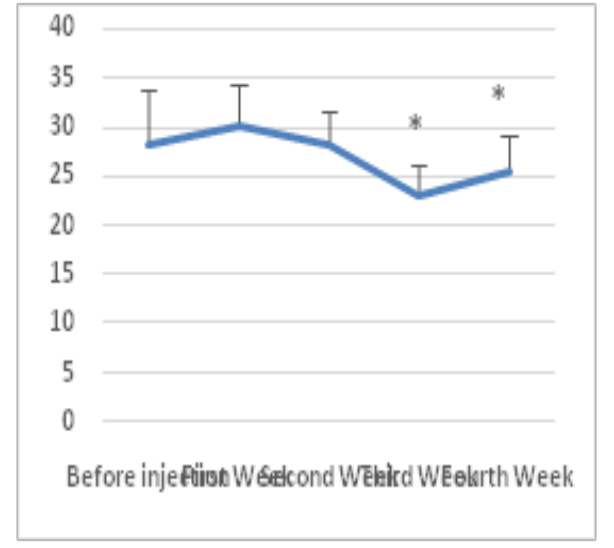

Figure 3 MDA

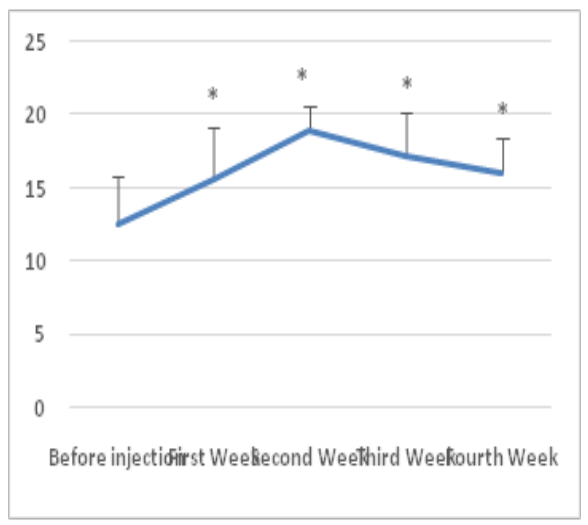

Figure 4 Plasma globulin g/dl.

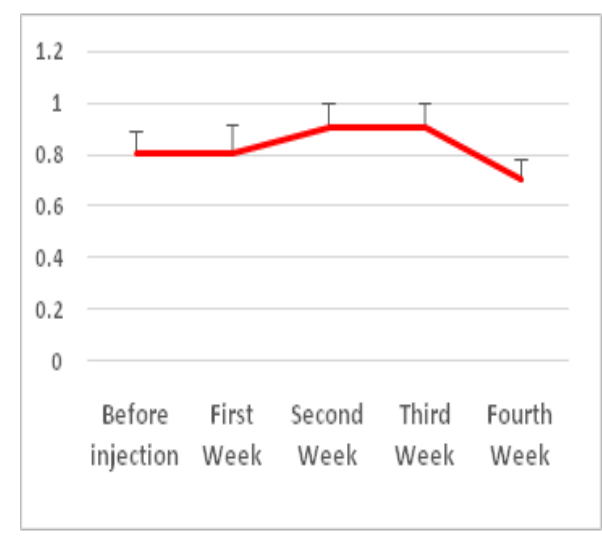

Figure 5 Ascorbic acids mg/dl.

Total serum globulins (Figure 4) increased significantly by the $1^{\text {st }}$ and the $4^{\text {th }}$ week respectively post intravenous infusion, while and ascorbic acid (Figure 5) increased but not significantly. Daily ingestion of $20 \%$ solution from floral-undetected Nigerian honey ${ }^{65}$ or intraperitoneal of $10 \%$ Egyptian $^{66}$ fennel honey solution increased serum globulin and ascorbic acid levels, ${ }^{65}$ while daily ingestion of acasia Pakistanish honey up to $50 \%$ did not alter the serum globulin level. ${ }^{67}$ Vitamin $\mathrm{C}$ raises intracellular glutathione levels and playing an important role in protein thiol group protection against oxidation, so honey vitamin $\mathrm{C}$ content will magnify its antioxidant effect as the profound antioxidant efficacy might be due to the synergistic action of the polyphenols such as flavonoids, and other compounds such as vitamin C..$^{68}$

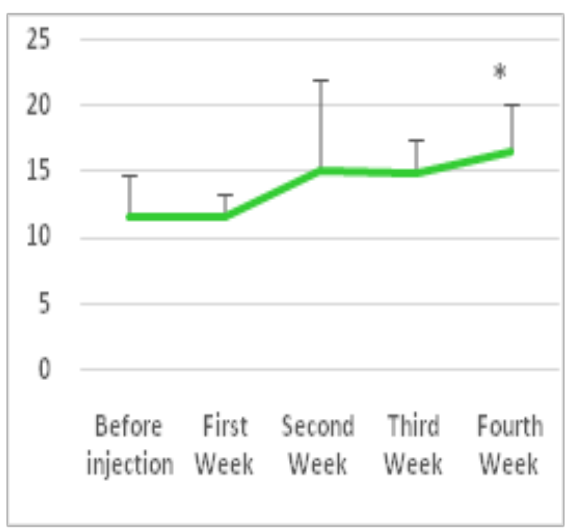

Figure 6 Total Leucocytic count $(x \mid 03 / \mu l)$.

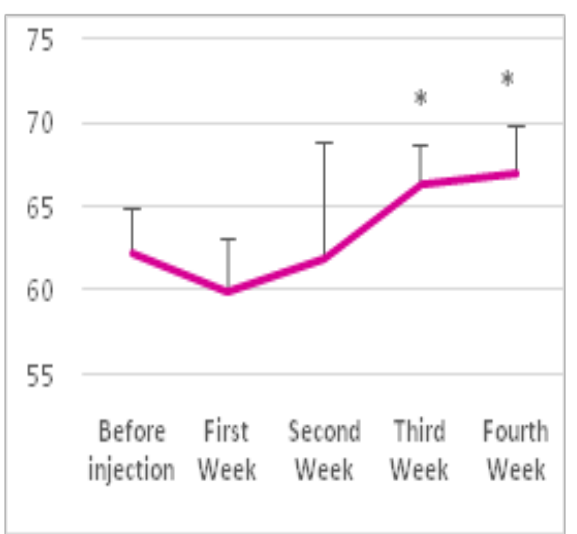

Figure 7 Lymphocytes \%.

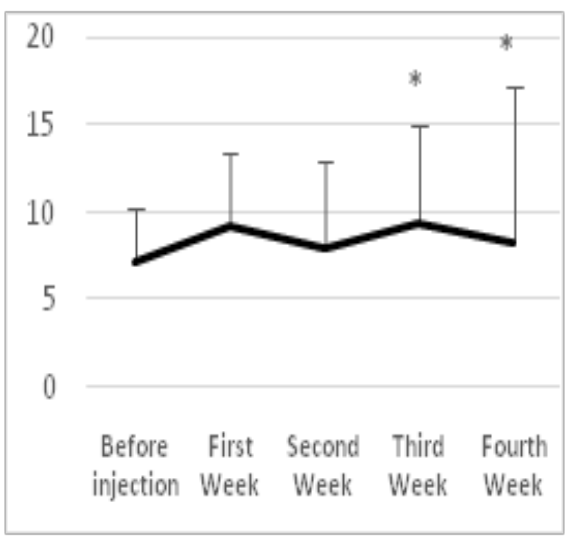

Figure 8 Monocytes \%.

The leucogram revealed that TWBCs elevated significantly by the $4^{\text {th }}$ week post intravenous infusion (Fiure 6), where the percentages of lymphocytes (Figure 7) and monocytes (Figure 8) increased significantly by the $3^{\text {rd }}$ week. Ingestion of daily honey solution increased total WBCs, lymphocytes ${ }^{41,66,69}$ and monocytes. ${ }^{41,66,70}$ In the present study, intravenous honey infusion decreased segmented cells (Figure 9) significantly by the $3^{\text {rd }}$ week, while increased both band (Figure 10) and eosinophil cells (Figure 11) but not significantly.

In the present work, the leucogram also revealed that TWBCs 
elevated significantly by the $4^{\text {th }}$ (Figure 6), while lymphocytes (Figure 7), monocytes (Figure 8) and segmented cells (Figure 9) \% showed significant increase earlier by the $3^{\text {rd }}$ week post infusion. Ingestion of honey solution ameliorates the oxidative stressed toxic effects in rabbits (cadmium) ${ }^{69}$ and rats (hydrocarbon ${ }^{71}$ or induced malignancy ${ }^{72}$ elevating TWBCs and lymphocytes $\%$, rather than in breast cancer women. ${ }^{73} \mathrm{Also}$, honey ingestion elevated lymphocytes $\%$ in normal healthy human, ${ }^{74}$ quails. ${ }^{75}$ It is widely documented that all routes of honey administration improve blood indices especially, total leucocytic count, ${ }^{7,66}$ monocyte $\%^{41,66}$ and lymphocytes $\%{ }^{7,66,76}$ which may be due to that honey protects the oxidative damage of lymphocyte DNA. $^{4}$

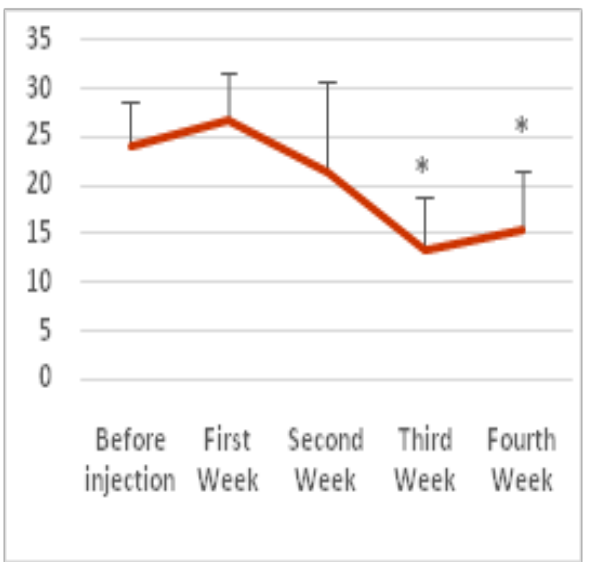

Figure 9 Segmented cells \%.

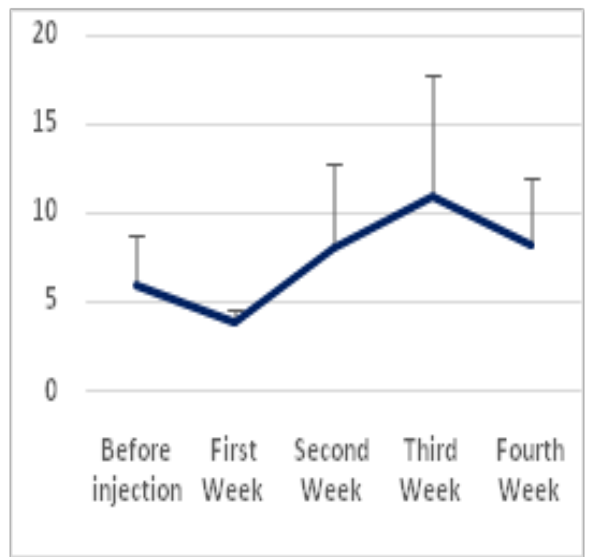

Figure IO Band cells \%.

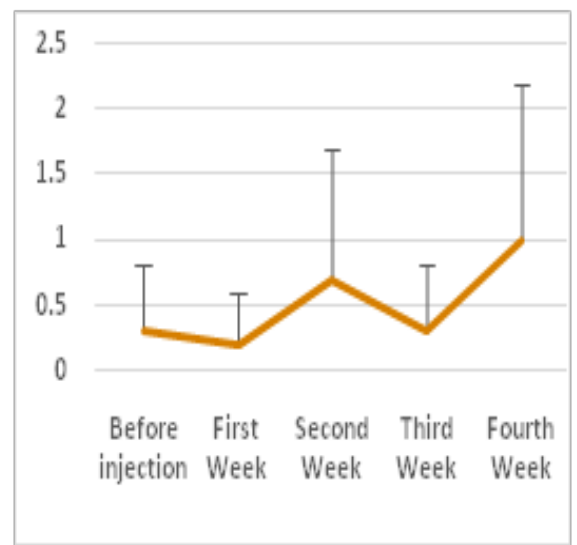

Figure I I Eosinphil \%.

\section{Conclusion}

It was concluded that rapid I/V infusion of Egyptian fennel 20\% honey solution in goats increased enzymatic antioxidants (GPX and SOD) and decreased the free radical metabolites (MDA). Moreover, it improved some heamo-indices; total leucocytic count, lymphocytes, monocytes percentages and total serum globulins. Although a risky factor of $25 \%$ anaphylactic shock was noticed, the obtained positive results are in need to further investigations to overcome this risky factor. Subsequently, I/V infusion of Egyptian fennel honey is a good antioxidative and free radicals scavenging apitherapy, rather than a heamo-improvement mediator.

\section{Acknowledgements}

None.

\section{Conflict of interest}

The authors declare that there are no conflicts of interest.

\section{References}

1. Horn H. Honey in medicine. Dtsch Med Wochenschr. 2013;138(5152):2647-2652.

2. Javadi SMR, Hashemi M, Mohammadi Y, et al. Synergistic effect of honey and Nigella sativa on wound healing in rats. Acta Cir Bras. 2018;33(6):518-523.

3. Elhorbity MA, Gertallah LM, Mansour MI, et al. Food Bee Honey versus Conventional Antiseptic in local management of Acute Infected wounds. $J$ Surgery Emerg Med. 2018;1:15

4. Cheng N, Wang Y, Cao W. The Protective Effect of Whole Honey and Phenolic Extract on Oxidative DNA Damage in Mice Lymphocytes Using Comet Assay. Plant Foods Hum Nutr. 2017;72(4):388-395.

5. Sairazi MN, Sirajudeen KN, Muzaimi M, et al. Tualang Honey Reduced Neuroinflammation and Caspase-3 Activity in Rat Brain after Kainic Acid-Induced Status Epilepticus. Evid Based Complement Alternat Med. 12018:7287820.

6. A1-Waili NS, Lootah S. Safety and effectiveness of repeated intravenous infusion of natural honey on haematological and biochemical investigations in sheep. FASEB J. 2001;15:A136.

7. Al-Waili NS. Intravenous and intrapulmonary administration of honey solution to healthy sheep: effects on blood sugar, renal and liver function tests, bone marrow function, lipid profile, and carbon tetrachlorideinduced liver injury. J Med Food. 2003;6(3):231-247.

8. Abdulrhman M. Honey Injections Used to Treat Rheumatoid Arthritis: Honey Therapy for Rheumatoid Arthritis, A Case Study. Passau, Germany: 5th German Apitherapy Congress; 2007.

9. Abdul-Hafeez MM, Ali MM, Abdel-Rahman MF, et al. Antibacterial Activity of Honey for Treatment of Subclinical Bovine Mastitis: 2Intramammary Infusion as a Tool to Manage Non Responding Antibiotic Cases. 8th Sci Cong, Egypt: Egyptian Society for Cattle Diseases; 2005.

10. Wahba NM, El Nisr NA, Hamuda SM, et al. Intramammary honey infusion: A new trend in the management of subclinical mastitis. Journal of Animal and Veterinary Advances. 2011;10(20):2740-2744.

11. Abdul Hafeez MM, Abdul Kader HA, Sayed AM, et al. A bacteriological study of bovine endometritis, with special reference to its treatment with honey infusion. Assiut Vet Med J. 2001;45(89):289-302.

12. Zine el Abidine, Bouabdellah. Diagnosis and Treatment of Endometritis with Intra-Uterine Infusion of A Solution of Honey $70 \%$ in Mares. $J$ Vet Sci Technol. 2018;9:499.

13. Afrin S, Forbes-Hernandez TY, Gasparrini M, et al. Strawberry-Tree 
Honey Induces Growth Inhibition of Human Colon Cancer Cells and Increases ROS Generation: A Comparison with Manuka Honey. Int $J$ Mol Sci. 2017;18(3):E613

14. Almasaudi SB, Abbas AT, Al-Hindi RR, et al. Manuka Honey Exerts Antioxidant and Anti-Inflammatory Activities That Promote Healing of Acetic Acid-Induced Gastric Ulcer in Rats. Evid Based Complement Alternat Med. 2017;2017:5413917.

15. Tang SP, Kuttulebbai Nainamohamed Salam S, Jaafar H, et al. Tualang Honey Protects the Rat Midbrain and Lung against Repeated Paraquat Exposure. Oxid Med Cell Longev. 2017;2017:4605782.

16. Goon J, Choor C, Ainaa R, et al. Effect of nenas honey supplementation on the oxidative status of undergraduate students. Acta Alimentaria. 2014;43(1):182-190.

17. Sahhugi Z, Hasenan SM, Jubri Z. Protective Effects of Gelam Honey against Oxidative Damage in Young and Aged Rats. Oxid Med Cell Longev. 2014;2014:673628.

18. Afroz R, Tanvir EM, Hossain MF, et al. Protective Effect of Sundarban Honey against Acetaminophen-Induced Acute Hepatonephrotoxicity in Rats. Evid Based Complement Alternat Med. 2014;2014:143782.

19. Alqarni A, Owayss A, Mahmoud A. Physicochemical characteristics, tota phenols and pigments of national and international honeys in Saudi Arabia. Arabian Journal of Chemistry. 2016;9(1):114-120.

20. Al-Yahya M, Mothana R, Al-Said M, et al. Attenuation of CCl4-Induced Oxidative Stress and Hepatonephrotoxicity by Saudi Sidr Honey in Rats. Evid Based Complement Alternat Med. 2013;2013:569037.

21. Anand S, Pang E, Livanos G, et al. Characterization of Physico-Chemical Properties and Antioxidant Capacities of Bioactive Honey Produced from Australian Grown Agastache rugosa and its Correlation with Colour and Poly-Phenol Content. Molecules. 2018; 23(1):E108.

22. Shi P, Chen B, Chen C, et al. Honey reduces blood alcohol concentration but not affects the level of serum MDA and GSH-Px activity in intoxicated male mice models. BMC Complement Altern Med. 2015;15:225.

23. Liben T, Atlabachew M, Abebe A. Total phenolic, flavonoids and some selected metal content in honey and propolis samples from South Wolo zone, Amhara region, Ethiopia. Cogent Food \& Agriculture. 2018;4(1):1475925.

24. El-Borai A, Youssef G, Ghareeb D, et al. Antibacterial and Antioxidan Activities of Different Varieties of Locally Produced Egyptian Honey. Egypt J Bot. 2018;58(1):97-107.

25. Hegazi H, Tahtawy R, Abd Allah F, et al. Antitumor and Antioxidant Activity of Honey in Mice Bearing Ehrlich Ascites Carcinoma. Academic Journal of Cancer Research. 2014;7(3):208-214,

26. Escriche I, Kadar M, Juan-Borrás M, et al. Suitability of antioxidan capacity, flavonoids and phenolic acids for floral authentication of honey. Impact of industrial thermal treatment. Food Chem. 2014;142:135-143.

27. Fernandez-Cabezudo M, El-Kharrag R, Torab F, et al. Intravenous Administration of Manuka Honey Inhibits Tumor Growth and Improves Host Survival When Used in Combination with Chemotherapy in a Melanoma Mouse Model. Plos One. 2013;8(2):e55993.

28. Kassim M, Mansor M, Al-Abd N, et al. Gelam Honey Has a Protective Effect against Lipopolysaccharide (LPS)-Induced Organ Failure. Int J Mol Sci. 2012;13(5):6370-6381.

29. Buege J, Aust S. Microsomal lipid peroxidation. Methods Enzymology. 1978;52:302-310.

30. Kraus R, Ganther H. Reaction of cyanide with glutathione peroxidase. Biochem Biophys Res Commun. 1980;96(3):1116.

31. Misra H, Fridovich I. The role of superoxide anion in the autooxidation of epinephrine and a simple assay for superoxide dismutase. $J$ Biol Chem. 1972;247(10):3170-3175.

32. Roe JH. Standard Methods of Clinical Chemistry. In: Sellgson D, editor, New York: Scad Press; 1961. 35 p

33. Mstat-C Software program Mstat-C Michigan State University, Version 2.10. 1988

34. Inoue M, Sato EF, Nishikawa M, et al. Mitochondrial generation of reactive oxygen species and its role in aerobic life. Curr Med Chem. 2003;10(23):2495-2505.

35. Ricoux R, Lukowska E, Pezzotti F, et al. New activities of a catalytic antibody with a peroxidase activity: formation of $\mathrm{Fe}(\mathrm{II})-\mathrm{RNO}$ complexes and stereoselective oxidation of sulfides. Eur $J$ Biochem. 2004;271(7):1277-1283

36. Hilary S, Habib H, Souka U, et al. Bioactivity of arid region honey: an in vitro study. BMC Complement Altern Med. 2017;17(1):177.

37. Jóhannesson T, Gudmundsdóttir KB, Eiríksson T, et al. Selenium and GPX activity in blood samples from pregnant and non-pregnant ewes and selenium in hay on scrapie-free, scrapie-prone and scrapie-afflicted farms in Iceland. Icel Agr Sci. 2005;16/17:3-13.

38. Stahl W, Sies H. Antioxidant activity of carotenoids. Mol Aspect Med $2003 ; 24: 345-351$

39. Chen Y, Saari JT, Kang YJ. Weak antioxidant defenses make the heart a target for damage in copper-deficient rats. Free Rad Bio Med. $1994 ; 17 \cdot 529-536$

40. McCall MR, Frei B. Can antioxidant vitamins materially reduce oxidative damage in humans? Free Rad Biol Med. 1999;26:1034-1053.

41. Tonks AJ, Cooper RA, Jones KP, et al. Honey stimulates inflammatory cytokine production from monocytes. Cytokine. 2003;21(5):242-247.

42. Khalil M, Boukraa L. Antioxidant Properties of Honey and Its Role in Preventing Health Disorder. The Open Nutraceuticals Journal. 2010;3:616

43. Meda A, Euloge Lamien C, Romito M, et al. Determination of the tota phenolic, flavonoid and proline contents in Burkina Fasan honey, as well as their radical scavenging activity. Food Chem. 2005;91:571-577.

44. Vela L, De Lorenzo C, Pérez RA. Antioxidant capacity of Spanish honeys and its correlation with the polyphenolic content and other physicochemical properties. J Sci Food Agric. 2007;87:1069-1075.

45. Mani R, Natesan V. Chrysin: Sources, beneficial pharmacological activities, and molecular mechanism of action. Phytochemistry. 2018;145:187-196.

46. Pérez RA, Iglesias MT, Pueyo E, et al. Amino acid composition and antioxidant capacity of Spanish honeys. J Agric Food Chem. 2007;55(2):360-365.

47. Abdulazez MK, Yusoff KM. Honey extracts have 'potent' antiInflammatory, analgesic effect: Identification of polyphenolic antioxidants from honey methanol and ethyl acetate extracts and their antiinflammatory and antinociceptive activities. The 6th German Apitherapy and Apipuncture Congress held in Passau from March 27th to April 1st, 2008. 2008 .

48. Escriche I, Kadar M, Juan-Borrás M, et al. Suitability of antioxidan capacity, flavonoids and phenolic acids for floral authentication of honey. Impact of industrial thermal treatment. Food Chem. 2014;142:135-143.

49. Yu XM, Phan T, Patel PN, et al. Chrysin activates Notch1 signaling and suppresses tumour growth of anaplastic thyroid carcinoma in vitro and in vivo. Cancer. 2013;119(4):774-781.

50. Xue C, Chen Y, Hu DN, et al. Chrysin induces cell apoptosis in human uvea melanoma cells via intrinsic apoptosis. Oncol Lett. 2016;12(6):4813-4820. 
51. El-Haskoury R, Kriaa W, Lyoussi B, et al. Ceratonia siliqua honeys from Morocco: Physicochemical properties, mineral contents, and antioxidant activities. J Food Drug Anal. 2018;26(1):67-73.

52. Wardlaw A, Kay A. Interrelationship between $\mathrm{T}$ lymphocytes and eosinophils. In: Eosinophils: Biological and Clinical Aspects. In: Makino, S, Fukuda, T, editors. Boca Raton: CRC Press; 1992. p. 261-271.

53. Musstafa FB, et al. Honey bee venom secretory phosphlipase A2 induces leukotriene production but not histamine release from human basophiles. Clin Exp Immunol. 2008;151(1):94-100.

54. Almasaudi S, El-Shitany N, Abbas A, et al. Antioxidant, Antiinflammatory, and Antiulcer Potential of Manuka Honey against Gastric Ulcer in Rats. Oxid Med Cell Longev. 2016;2016:3643824.

55. Halawa H, El-Nefiawy N, Makhlouf N, et al. Evaluation of honey protective effect on lead induced oxidative stress in rats. JASMR. 2009;4(2):197-208.

56. Erejuwa O, Sulaiman S, Ab Wahab M, et al. Honey supplementation in spontaneously hypertensive rats elicits antihypertensive effect via amelioration of renal oxidative stress. Oxid Med Cell Longev. 2012;2012:374037.

57. Sahhugi Z, Hasenan S, Jubri Z. Protective effects of Gelam Honey against oxidative damage in young and aged rats. Oxid Med Cell Longev. 2014:673628

58. Ghazali W, Mohamed M, Sulaiman S, et al. Tualang honey supplementation improves oxidative stress status among chronic smokers. Toxicological \& Environmental Chemistry. 2015;97(8):1017-1024.

59. Al-Rahbi B, Zakaria R, Othman Z, et al. Protective Effects of Tualang Honey against Oxidative Stress and Anxiety-Like Behaviour in Stressed Ovariectomized Rats. Int Sch Res Notices. 2014;2014:521065.

60. Sani N, Belani L, Sin C, et al. Effect of the combination of gelam honey and ginger on oxidative stress and metabolic profile in streptozotocin-induced diabetic Sprague-Dawley rats. Biomed Res Int. 2014;2014:160695.

61. Ahmad R, Hussain M, Saeed F, et al. Phytochemistry, metabolism, and ethnomedical scenario of honey: A concurrent review. International Journal of Food Properties. 2017;70(1):254-S269.

62. Arabmoazzen S, Sarkaki A, Saki G, et al. Antidiabetic effect of honey feeding in noise induced hyperglycemic rat: involvement of oxidative stress. Iran J Basic Med Sci. 2015;18(8):745-751.

63. Jaganathan SK, Mandal M. Antiproliferative effects of honey and of its polyphenols. J Biomed Biotechnol. 2009;2009:13.

64. Samarghandian S, Farkhondeh T, Azimi-Nezhad M, et al. Protective Effects of Chrysin against Drugs and Toxic Agents. Dose Response. 2017;15(2):1559325817711782.
65. Oke O, Sorungbe F, Abioja M, et al. Effect of different levels of honey on physiological, growth and carcass traits of broiler chickens during dry season. Acta argiculturae Slovenica. 2016;108(1):45-53.

66. Neveen A EL-Nisr, Abd El Rahman MF, Ghada A Abou El-Ella, et al. Immunomodulatory response of Apitherapy. I- Bioassay of some Apiproducts and their influence on haemo-immunodynamics in rats. Villa Mondragone Roma, Italy: Apimedica and Apiquality 2nd International Fourum 9-12; 2008.

67. Aliyu M, Odunola O, Owumi S, et al. Daily Consumption of Honey: Effects on Male Wister Albino Rats. International Journal of Food Nutrition and Safety. 2012;1(2):66-74.

68. Naziroğlu M, Butterworth PJ. Protective effects of moderate exercise with dietary vitamin $\mathrm{C}$ and $\mathrm{E}$ on blood antioxidative defense mechanism in rats with streptozotocin-induced diabetes. Can J Appl Physiol. 2005;30(2):172-185.

69. Abdelaziz I, Elhabiby MI, Ashour AA. Toxicity of cadmium and protective effect of bee honey, vitamins $\mathrm{C}$ and B complex. Hum Exp Toxicol. 2013;32(4):362-370.

70. Benhanifia M, Boukraâ L, Hammoudi S, et al. Recent patents on topical application of honey in wound and burn management. Recent Pat Inflamm Allergy Drug Discov. 20111;5(1):81-86.

71. Achuba F, Nwokogba C. Effect of honey supplementation on heamatological parameters of wistar albino rats fed hydrocarbon contaminated diets. Biokemistri. 2015:27(1)

72. Ahmed S, Othman N. The anti-cancer effects of Tualang honey in modulating breast carcinogenesis: an experimental animal study. BMC Complement Altern Med. 2017;11;17(1):208.

73. Zakaria Z, Zairos F, Siew H, et al. Effects of honey supplementation on safety profiles among postmenopausal breast cancer patients. Journal of Taibah University Medical Sciences. 2018

74. Al-Waili NS, Saloom KY, Al-Waili TN, et al. Influence of various diet regimens on deterioration of hepatic function and hematological parameters following carbon tetrachloride: a potential protective role of natural honey. Nat Prod Res. 2006;20(13):1258-1264.

75. Babaei S, Rahimi S, Karimi Torshizi MA, et al. Effects of propolis, royal jelly, honey and bee pollen on growth performance and immune system of Japanese quails. Vet Res Forum. 2016;7(1):13-20.

76. Al-Waili NS, Boni NS. Lowering effect of natural honey on plasma prostaglandins concentrations in normal nndividuals. $J$ Med Food. 2003;6(2):129-133. 